Falseiling

Inkjet print on $1 / 4^{\prime \prime}$ MDF installed in drop ceiling grid

$24 " \times 24^{\prime \prime}$

Based on an urban myth in India, where people often question the use of drop (fall) ceiling in households wondering if they are hiding money up there; this series was my interpretation of what we are hiding. For me, this meant a literal exposure of what was exactly above each drop ceiling tile. My work does not happen to you, you happen upon it through subtle interventions I create. These interventions demand the viewer to introspect the space and my work makes visible the unnoticed elements of that space. After the viewers suspension of disbelief, there is a discrepancy in the moment of realisation, that my work is trying to be something it's not while simultaneously blending into the environment. This discrepancy is not alarming, but grows exponentially as one spends time with it, leaving little grasp of what is real and what is not.

\section{Artist Statement}

I question our need to conceal unseen systems and our compliance with forceful self-categorisation Through subtle alterations of documents, images, and spaces, I displace normative expectations and evaluate the systemic bias and hierarchy within such institutional systems. In doing so, my practice relies heavily on the materiality of institutional space and works to make invisible labour visible.

I often consider the wall as a metaphor for transparency. Though it is commonly thought to block or segregate, my laboring on, replication, documentation, and illusory presentations of the wall seek to blur the line between falsehood and reality. In blurring this line, I present a form of clarity that contradicts the facade that is typically presented. In my futile attempts to rectify this lack of clarity, I often refer directly to my participation in these systems as a nonresident alien without a last name. Futility is an importan concept in my practice. I play on the idea of "filling out a form " for instance, by laser etching into drywal and using spackle to answer the prompts - redacting, erasing, and in a sense finishing the wall as I refill the surface. I set conditions for my projects that are intended for the end result to counteract my alterations and restore the material back to its original state. My work happens after the condition has been se and before it has been fulfilled.

These systems exude hierarchical power and rely on expendability, impermanence, and catergorisation to maintain a permanent state of temporariness for an individual. This temporariness then translates into the labour that I perform, the place which I occupy, and the state of my being: a non-resident alien who does not have a last name.
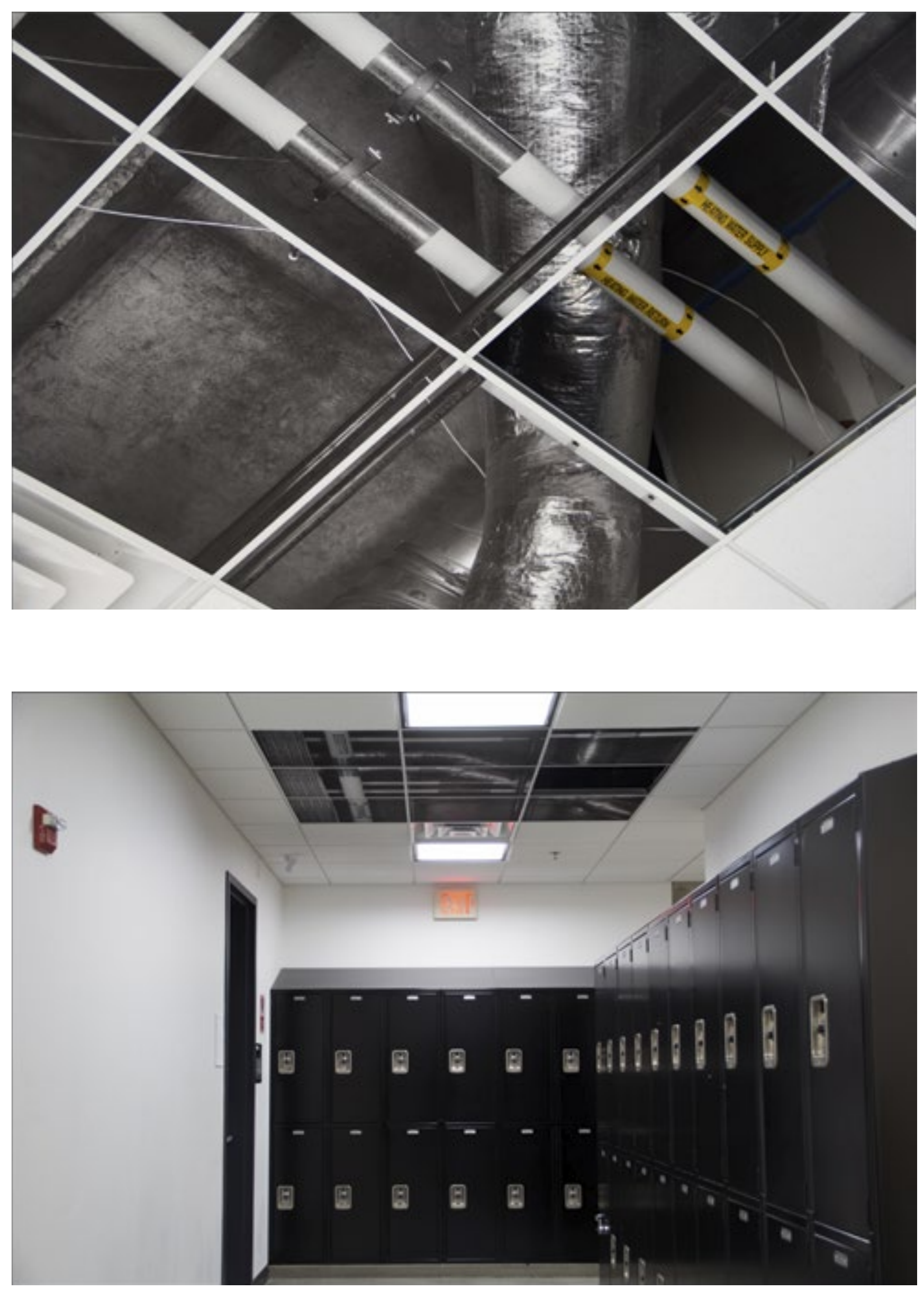


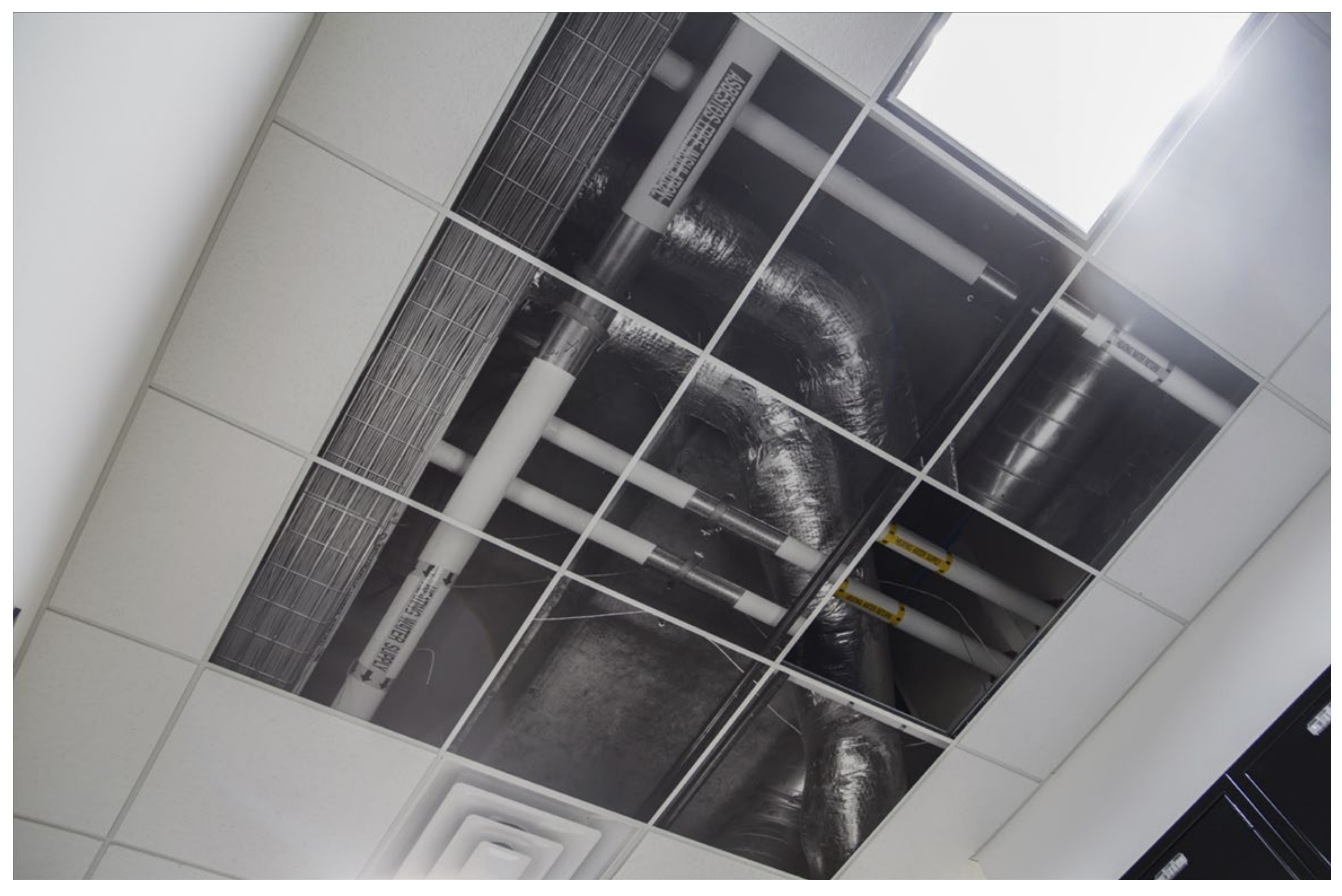


